\title{
Elements of Communicativity and Informativity in the Text
}

\author{
Gulmar Israfilova ${ }^{1}$ \\ ${ }^{1}$ Department of Lingua-Culturology, Azerbaijan University of Languages, Baku, Azerbaijan \\ Correspondence: Gulmar Israfilova, Department of Lingua-Culturology, Azerbaijan University of Languages, \\ Baku, Azerbaijan. E-mail: gulmar-tx@rambler.ru
}

Received: December 12, 2014 Accepted: January 2, 2015 Online Published: January 27, 2015

doi:10.5539/ijel.v5n1p190

URL: http://dx.doi.org/10.5539/ijel.v5n1p190

\begin{abstract}
The article deals with the categories of the art text that create chances for the birth of various associations which function as the main condition of communicativity. The categories of the art text serve the goal of the creation of texts, functionalization of the individual style. Text is an organized system. The main elements, components, means that connect these components and the categories of the text are investigated. At the same time the means of modality, their features and functions, communicative context elements that also play an important role in the formation of the category of modality, in the birth of the modal background are widely researched in the article.
\end{abstract}

Keywords: communication, stylistics, informative, communicative, syntactical units, decomposition, theme, modality,conseptual, features, devision, recaputilation

\section{Introduction}

In connection with the development of the human consciousness and society the means of expression of the thought undergo perfection; as a result of the historical progress a number of the means of comprehension and expression are replaced by others, which acquire a new quality reflecting the transition from the concrete primitive thinking to the abstract thinking. In this connection I.I. Menshikov, a prominent linguist, noted that the changing labor conditions in the society must find their reflection in the means of communication, too.

At the present stage of theoretical linguistics the syntax of a number of languages falls into three: traditional, communicative and structural. The traditional and communicative syntaxes in this classification include spans of speech larger than the sentence and text. In this case the sentence is approached as the smallest unit of the text and as the basic unit expressing the thought, because the oral and written communications are held on the text level.

The sentence being the primary and basic linguistic form of expressing the thought, its structure and sense require logical analysis. In the very communicative syntax the interrelation of thinking and language, speech and its units become visible. In this process the sentence is not subjected to the division or grouping of its members only, it is also divided according to its sense and elements from the point of view of the importance of information. In this process the syntactical units function like logical-grammatical and stylistic units.

\section{Art text}

In modern linguistics one of the basic problems is the communicativeness of the language, therefore the functional aspects of the linguistic phenomena have moved to the forefront in the linguistics of the text. The belles-lettres style differs from scientific, popular writing, official and other styles for being richer and colorful in aesthetic traits, means of expression, therefore the interpretation of its semantic layers is not limited. The theoretical literature has mentioned a number of distinguishing features of the belles-lettres style. The basic distinguishing feature of the belles-lettres style is symbolism. The very symbolism ensures not only the comprehension of the recipient, but also the communicativeness of the text and speech. I. Kudrevatikh mentions the following peculiarities of the belles-lettres style: 1) quality types of semantic layers, 2) dialogue, 3) difficulty of comprehension, that is, comprehension as a result of repeated reading (Kudrevatikh, 2001).

One of the basic structural elements of the art text is its composition. Theoretical literature defines it as a complex which determines the formal relations in the text and its conformity, or its synthesis. The differences in the compositions of prosaic and poetic works emerge on the grounds of internal division of the parts of the work. An internal organization is characteristic to prose. In connection with the problem of thematic composition it is 
expedient to consider such interconnected notions as the theme, motive, and plot. In the linguistic analysis of the lyric work the composition, as well as the text-forming function of repetition must be studied in its interrelation with the thematic development, replacement and correlation of semantic units.

Art texts are not only bearers of information; they also exert an aesthetic impact on the reader with the help of a specific organization of words in the text. By laying a focus on a definite word leads to a new order of words in the text. In general, repetitions in different parts of the text acquire different structures.

One of the features which turn the art text into a communicative speech is the functional-semantic and stylistic categories inherent to it. The intra-linguistic and extra-linguistic relations in the art text, the features of interrelation of lexical-semantic and stylistic levels in the organization of speech structure determine the functional-stylistic meaning of those categories.

The category of modality in the art text influence various linguistic levels and assist the formation of other text categories like time and space, "the image of the author", "the image of the narrator", etc., and thus, exerts a strong impact on the communicativeness of the expressive function of the language. The means of modality create conditions for the merge of contact and distant sentences in the text. In some cases the means of modality in the sentences located in considerable distance from each other a factor for merging the syntactical units of a whole art text. The means of modality on the text level possess two features: they fulfill the function of integration and allow define the individual style of the author and create the idiosyncrasies of personages. The integrating function of the means of modality emerges in the interrelation of functional-semantic and stylistic categories. By the determination of the individual style of the author we mean the discovery of the additional structural-semantic plane in the text, which is the discovery of the source of information and of that information by the subject. The modal words used in the text by the author play one of the main roles in it, so that the modal words demonstrate the adherence of the author in the process of narration. To ignore the modal words in the narration means that the author is objective in his judgment. By making a peculiar use of the means of modality the author demonstrates his own participation in the narration, displays his attitude to the events and characters in that narration. F. Jahangirov notes that communicative context elements also play an important role in the formation of the category of modality, in the birth of the modal background. A number of extra-linguistic means take part in the communicative context along with the linguistic forms of expression, it plays an important role in the process of realization of modal meanings (Jahangirov, 2005).

Thus, analysis on the level of integrative features of syntactical units of the art text as the form of the communicative speech allow determine the peculiarities of the usage of lexical-grammatical and stylistic structures on the level of integrative relations of syntactical units of the art text as the form of the communicative speech. The categories of the art text serve the goal of the creation of texts, on the one hand, functionalization of the individual style, on the other hand; these categories create chances for the birth of various associations which function as the main condition of communicativity.

\section{Expressiveness in the Language}

Expressive function of speech and word has always been in the focus of attention of the linguists. The problem of expressiveness is one of the cardinal problems of linguistics, because it is connected with the emotional attitude of the speaker (write) to the idea expressed in the text. Rationalism and emotionality merged on subjective and objective basis are inseparably interconnected with expressiveness in the process of speech. Live speech is expressive, as a rule, because the emotions of the speaker find their expression in it along with the expression of the objective reality. Both the forms of scientific or "serious" business speeches are not deprived of expressive shades. But the mechanism of creation of such shades is multi-color and multi-plane.

By expressive lexicon we mean the units which condition the realization of the expressive function of the language. Such language units demonstrate the imagination of the speaker about the quality and quantity of the real object, the feature of that object is moved to the fore front. Expressive lexical unit fulfills the nominative function, too, the normative degree of the words are not one and the same, because the expressive lexical units do not fulfill the function of naming only the real objects.

The language mechanism has been built in the form which allows involve actively a whole system of figurative expressive forms in naming along with independent, direct and indirect forms of naming, as well as naming by a sign directly. The artistic-poetic structure of the language, its amazing richness and color emerge in the complicated synthesis of its multi-layer, multi-branch relations and means of impact. Whole figurative sentence-thoughts along with figurative word-notion play an important role in the building of art texts; constancy of affirmation-negation occupies the central place for bringing to light the character of the poetic communication. In critical theoretical literature the mechanism of figurativeness, which is one of the leading forces of the 
expressive potential of the language, the poetic resources of sentence-metaphors and different means of their poetic expression have been subjected to detailed studies. At present there is a need for the study of the variegated manifestations of expression of those language means in the art text, for discovering the weak and strong points lying in the depth layers, and which generalize the practice of speech of the art text on these foundations.

According to V. V. Vinogradov, one of the prominent scholars of XX century, the goal of the theoretical thinking is to cognize the world logically, but the function of the artistic thinking is the cognition of the world creatively (Vinogradov, 1981). The creative fantasy in artistic thinking leads to the formation of concrete and polysemantic imagery and symbols simultaneously. The existence of the poetic speech is determined on the basis of emotional-figurative expression of the reality in conformity with this or other aesthetic demands. Any poetic phenomenon may be poetic. D. N. Shmeleva thinks that the aesthetic (poetic) function of the language lies in the use of the potentials within the poetic language. These potentials exist in the phonemic organization of speech, in the motivation of the means of expression in our consciousness (Shmeleva, 1997).

E. Sapir also sounded valuable thoughts concerning the important differences between the languages of the art and scientific texts. According to him, the scientific truth is not individual in nature, it has not been provided with a special language. Thus, the means belonging to the language of science is a kind of generalized language, a kind of symbolic algebra. An adequate translation of the scientific text is possible, because an original expression is a translation in fact. But the art text is individual and concrete. Being "woven" from the form and substance of a concrete language, the art text fits the structure of its mould and features. The writer never thinks whether it is narrow or wide, or depends on this mould. But there emerges the issue of translation of his work to another language; the real nature of the original mould becomes visible. Each language in itself is an art of collective expression. It embodies the sum of special aesthetic factors such as phonetic, rhythmic, morphological, and word-building, word order. Men-of letters make use of the aesthetic sources inherent to the language (Sapir, 1966).

In the mid of the past century G. O. Vinokur disclosed very interesting and original conception about the poetic or figurative language (Vinokur, 1929). That conception can be expressed briefly like this: First of all, poetic language is the language of fiction; it is the language of the belles-lettres style, that is, the special functional style of the literary language. Secondly, by the notion of the poetic language one can speak about "special expressiveness", about expressive "language quality". The expression of "poetic language has a much more important meaning. If we accept the thesis which says that "language in itself is poetry", we can broaden the notion of the poetic function of the language some more and can say that poetic language is a figurative language. The meaning of the figurative (including non-metaphoric meanings) is not limited with the real meaning. Words in the poetic language are more subject to the general laws of the language than becoming the main figures of the language of fiction. Unlike the ordinary speech the users of the language of fiction (poets, writers) are based on the semantic load of the language units, therefore they use metaphoric means more than the rest. Authors of antiquity also noted the common-typological, philosophic-linguistic importance of the metaphor in the language of fiction: "There is nothing in the reality surrounding us that we are unable to name it by using notions from other spheres" (Cicero). Aristotle wrote that the metaphor is a transformation either from the form to the type, or an unordinary transformation on the basis of analogy. In the Linguistic literature transformations have the following extra-linguistic types: man-animal, animal-man, plant-animal, abstract notion-man, man-abstract notion, animal-abstract notion, man-thing, thing-man, etc.

Text differs from an ordinary heap of words, it is a source of information organized and directed in a specific form. Information depends on the completeness and wholeness of the text. Information in the art text provides the conformity of the text with the modern world, conditions its topicality. In one word, information is a psycho-linguistic phenomenon which joins "the distance of meanings," brings closer the pieces of history to each other.

Text is an organized system, and this system has its own elements which are its components, means which connect these components, and its categories. The study of these components is of great importance.

The categories of text pass to each other in any text in a peculiar form, and it impedes to distinguish a leading category. Very often the categories do not have formal elements in the text; they exist in it, but remain there unnoticed. It is more obvious in the category of informativity. Informativity embodies different issues of linguistic nature. These issues include the new problems of information, the distinguishing features of information, the importance and value of information and others. Now let us consider them separately. 
Any text must contain information. If several paragraphs repeat each other, repeat the same thing, that is, if they are the same in all parameters, these paragraphs lack information. Informativity requires differences. Separately taken sentences do not contain information. Informativity is inherent not to sentences, but to the text. In general, text serves the goal of conveying information to the reader.

The diggers produced coal manually, by using hacks for many years. Very often they stop the work, strengthen the stones (pillars) and continued the work again. Naturally it was a hard work and the productivity was low.

At the beginning of the 30s pneumatic hacks appeared. It was a great progress in the coal industry in those days. The expected that labor productivity will grow enormously, but it did not.

The problem was connected with the organization of labor. As in the previous times the digger would again lay the tool aside and begin to strengthen the pillars (Agayev, 1980).

This piece is taken from E. Agayev's "Atalardan Sorush" (Ask it from Fathers). The syntactical wholes which follow each other convey different information on the same topic. The author tries to clarify the information, its cause and effect. It becomes evident the reason of low labor productivity is not the use of hacks by the diggers, but the use of hacks. As a result, less coal is produced.

One of the main issues in informativity is the news in the information. He author always tries to convey new information to the reader through the text. But the conveyed information is not equally interesting and important for all the readers. The text may be new for one reader or listener and contain some information, for another it may be old and not contain anything new. If the reader gets acquainted with the text for the first time, it will arouse interest in him; all the information in the text will be new for him. But this text may be already known to the other reader; he may have some imagination about its content and the information in it. In this case there is not any news for him. It means that something new within a time may turn to something known after some time. The new information embodies the imagination and the changes about the environment.

Like all the living beings the birds are also ruthlessly subject to the laws of nature. It is the same with the fish. Let us take the sturgeon. For thousands of years, eternally, within a time divided for them, within a year they leave the sea and swim to the outfall of the river for spawning. Or the mysterious sea angles. Irrespective of the space where they live, the spot of the world where it is, it makes no difference for them, the cover thousands of miles and go the Saragossa Sea for population.

Another example:

The scene had changed, I found myself in a vast desert. It was covered with snow till the high mountains which surrounded the desert. A cold wind was blowing and raising the snow from the earth and scattering it in sea. Suddenly the snow from the heaven and on the earth mixed with each other and darkened all around. When the wind and the fall of snow thinned a little, the breast of the mountain became visible. I saw a woman was walking along the foot of the mountain taking a girl by the hand. The kerchief and the skirt of the woman surrendered to the wind waved in front of her.

In this text the author describes the events as they are. He enables them to have full imagination about the events and information described there.

Subjective information is a type of information in which the author conveys not objective information, the psychological and emotional information which he has in mind. For instance, a historian describes a historical even, war or battle by using facts and proofs. But the author of the fiction describes the same by adding elements inherent to belles-lettres style. In this case the text is not objective and, but subjective. It is the product of the author's thinking.

I. R. Galperin speaks about three types of information: Content -factual information, content-conceptual information and content subtextul information (Galperin, 1981).

Content-factual information conveys information on the past, present and future events in the world around us, on imaginary and true events and facts. Such information is encountered in all the texts. In art texts the information is conveyed by using imagery, texts on science use facts, proofs for proving the truthfulness of the information. Content-factual information conveys information on the world outlook of different scholars, their judgments, fact and proofs quoted by them, comparison of facts, the possible ways of solution of complicated and difficult problems and on the obtained results, etc. For example:

In future the Caspian may produce 60 million net profits a year; this figure is bigger than the previous one. In any case even at present the Caspian is sufficiently income producing space for the fisherman. 
Content-conceptual information conveys to the readers information on the relations among the notions, on the means of description of the content factual information, on their role in the social, economic, political, cultural life of the people, on the relations among separate individuals, the point of view of the author about their complicated, psychological and aesthetic-cognitive activities. Content conceptual information is expressed conspicuously all the time. Such information remains beyond the content of the whole work and introduces to the reader the impressions created in the imagination of the author, it also conveys the meaning of the artistic information on the relations, facts, events and processes to the listener or reader. For instance:

The nature which gifted great caravan roads of trade to Nakhchivan could not deprive its residences of the inevitable and kind sense of hospitality, peculiar to commerce. When history made Nakhchivan the road of the military marches, it had to bring up brave residents and teach them to fight with saber and arrow.

We must note that content conceptual information remains outside the content of the art text, that is, it does not come into unison with the idea of the text, and it require mental efforts and logical thinking to discover the conceptual information. But in content-conceptual information in scientific prose is expressed quite conspicuously.

Content-conceptual information is the bearer of subtext information. The author sometimes conveys his thought to the reader not directly and clearly, but indirectly. Subtext information is required for this purpose. It may have different reasons: historical situation, political situation, hidden criticism, etc.

Subtextual information may be comprehended not at once. One may discover much deeper content if the conceptual information is read repeatedly, if much attention is paid to separate parts of the text, if the conceptual information has been obtained through a fleeting look at the text. Content-subtextal information is encountered mostly in art texts, particularly in poetry.

Art texts must be classified by proceeding from functional styles and from the nature of the information. The texts are classified into diplomatic texts (pacts, treaties, memoranda, notes, appeals, protests, ultimatums, etc.), into art texts (novels, stories, fables, essays, verse, drama, pamphlets, etc.), popular writings (brief information in newspapers and magazines, interviews, etc.).

News is a type of information, it conveys information on an event which takes place at the moment of speech, or later. According to its nature news is existential. It acquaints the reader with some news. It must be exact, concrete, and unemotional. This type of news is encountered in newspapers, radio and television programs.

Azeri dance to be taught in Austria. Renowned Azeri dance, People's Artist Tamara Muradova has signed a contract with the Vienna-based Kivani club to teach the Austrian amateurs Azeri dances for a year. T. Muradova will also represent Azerbaijan in an international dance festival "Golf" with representatives from 50 nations in Austria in October.

News is far from conceptualism; therefore it is not emotional and subjective in nature, and it is easily translated from one language into another.

M. Glushko defined the means which created the means of communicativity and informativity like this: 1 ) formal grammatical (prepositions, conjunctions); 2) deictic (articles, personal and demonstrative pronouns, the words - there, how, then, the former, the latter); 3) syntactical. M. A. Halliday and R. Heinz call the means which take part in the semantic-structural organization of the text "cohesion". (Halliday, 1973) Under the name of "formal means of connation of structural-semantic structure of the text", A. Mammadov defines six of their types: 1) phonetic repetition (phonetic stylistic devices like alliteration, assonance); 2) Morphological repetition (repetition of the signs of gender, time, and case); 3) lexical repetition (full and incomplete repletion of words, that is, their repetition in different forms, and their zero repletion); 4) syntactical repetition ( full and incomplete repletion of the word order, chiasmus and others); 5) lexical-grammatical means (conjunctions, prepositions, determinants and others); 6) deictic elements (different types of pronouns articles, etc.). (Mammadov, 2001) In her monograph titled "Syntax of the Text", N. Novruzova classifies the means which connects the components of the text into three groups and calls them like the followings: lexical means (words-forms, lexical repetitions, use of homonyms, etc.), morphological means (conjunctions and connectives, modal words, particles, etc.), syntactical means (word order, order of sentences, syntactical repetitions, synonymy-parallelism). This classification is based mainly on the Azerbaijani language, nevertheless, we think that it is the most suitable and important classification.

\section{Result}

Taking all above-mentioned we come to the conclusion that informativity and communicativity are the main categories of the text. The study of these categories is of great importance. Very often categoeies do not have 
formal elements in the text, they remain unnoticed. After the research we can easily see this feature in the category of informativity. Any text must contain information. Informativity is peculiar not to sentences, but to the text. In general, text serves the goal of conveying information to the reader.

\section{References}

Agayev, E. (1980). Ask it from fathers. Baku.

Galperin, I. R. (1958). Abstracts of stylistics of English language. Moscow.

Galperin, I. R. (1981). Text as an object of liguistic research. Moscow: Science.

Halliday, M. A. K. (1973). The Functional Basis of Language - Class, Codes and Control. In Bernstein (Ed.), Applied Studies towards a Sociology of Language. Boston: Routledge \& Kegan Paul.

Halliday, M. A. K., \& Hasan, R. (1976). Cohesion in English. London: Longman.

Jahangirov, F. (2005). Semantic analyse of modality in English and Azerbaijain languages. Baku.

Kobrina, N. A., \& Korneyeva, E. A. (1965). An outline of modern English syntax. Moscow.

Koderick, A. J. (1995). English Syntax. Oxford University Press.

Kudrevatikh, I. P. (2001). Stylistic role of syntactical units in the structure of Russan literary text. Abstract, Minsk.

Mammadov, A. V. (2001). The system of formal uniting ways in forming a text. Baku: Science.

Meshanikov, I. (1967). Correlation of logical and grammatical categories. Language and intellection. Moscow.

Odintsov, V. V. (1980). Stylistics of text. Moscow.

Sapir, E. (1966). Language.

Shmeleva, T. V. (1977). Model of speech genre. Speech genres. Saratov.

Sossur, F. (1977). Works of linguistics. Moscow.

Vinogradov, V. (1981). Problem of Russian stylistics. Moscow

Vinokur, G. O. (1929). Culture of language. Moscow.

\section{Copyrights}

Copyright for this article is retained by the author(s), with first publication rights granted to the journal.

This is an open-access article distributed under the terms and conditions of the Creative Commons Attribution license (http://creativecommons.org/licenses/by/3.0/). 